
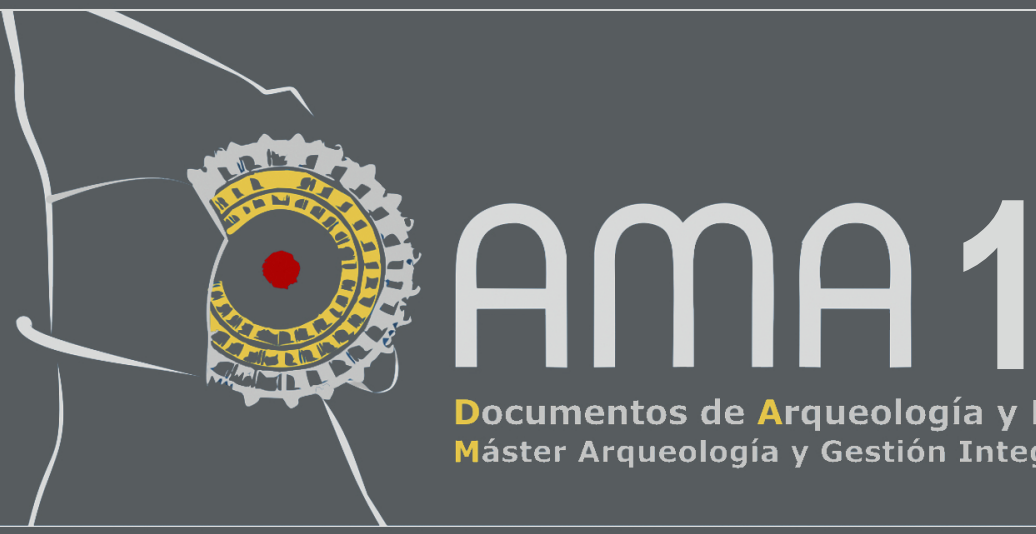

Documentos de Arqueología y Patrimonio Histórico

Máster Arqueología y Gestión Integral del Patrimonio de la Universidad de Alicante

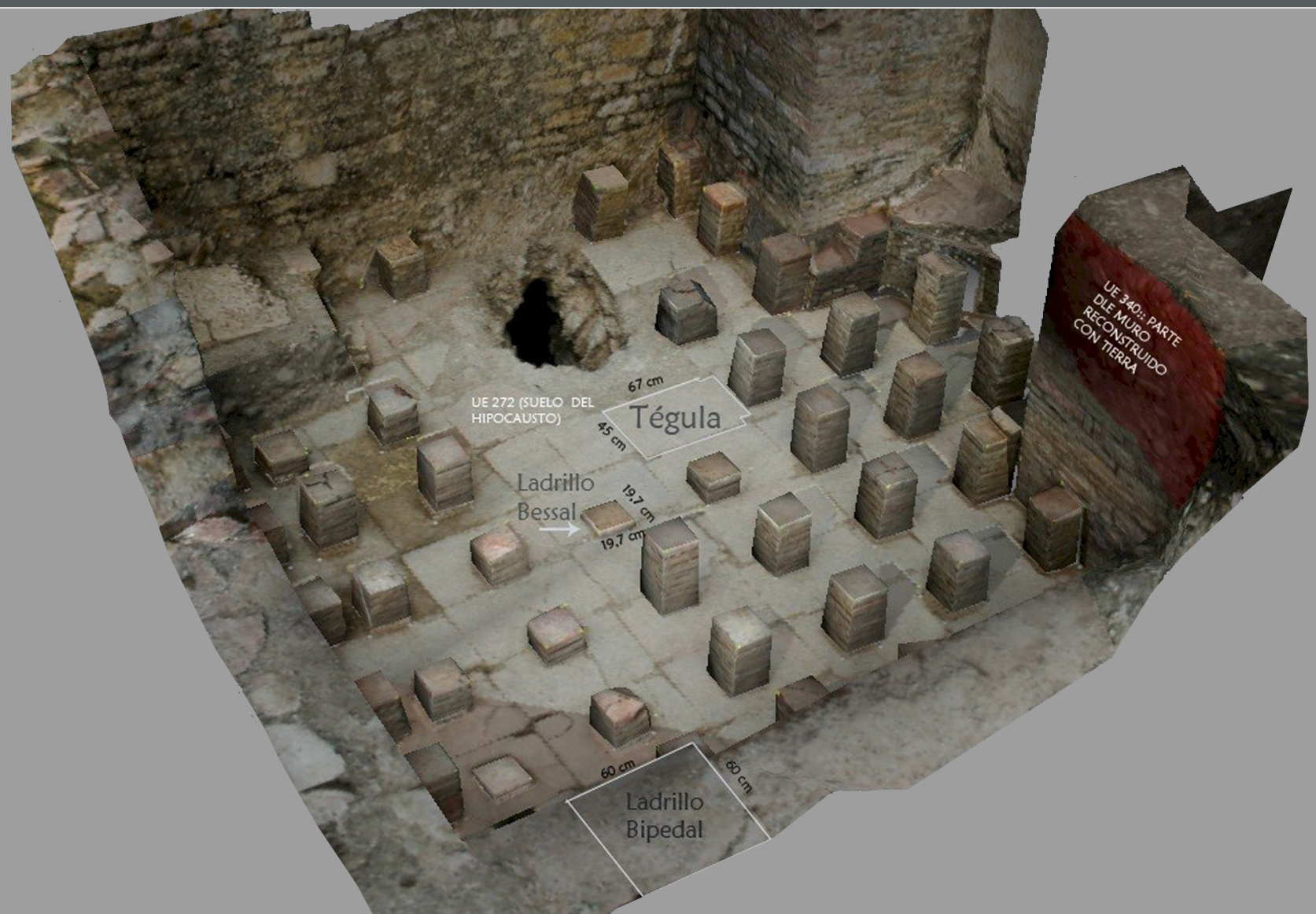

Documentos de Arqueología y Patrimonio Histórico Revista del Máster Universitario en Arqueología Profesional y Gestión integral del Patrimonio 



\section{DAMA 1}

\section{6}

DOCUMENTOS DE ARQUEOLOGÍA Y PATRIMONIO HISTÓRICO DEL MÁSTER UNIVERSITARIO EN ARQUEOLOGÍA PROFESIONAL Y GESTIÓN INTEGRAL DEL PATRIMONIO DE LA UNIVERSIDAD DE ALICANTE 


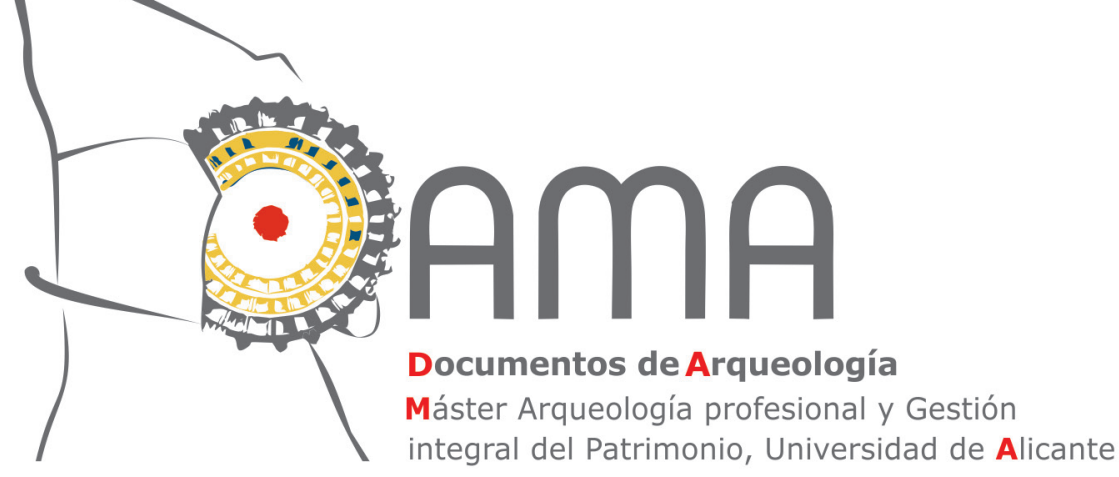

La revista electrónica DAMA. Documentos de Arqueología y Patrimonio Histórico surge como servicio para todos aquellos alumnos del Máster en Arqueología Profesional y Gestión Integral del Patrimonio de la Universidad de Alicante que se están iniciando en la investigación y cuya primera aportación a nuestra disciplina suele ser su Trabajo de Fin de Máster (TFM). Estos proyectos en muchos casos representan casi todo un curso de trabajo y esfuerzo, y con frecuencia quedan inéditos.

El objetivo de esta revista es ofrecer un medio que facilite la publicación de los resultados de sus TFM. La edición se presenta en versión digital y cuenta con su correspondiente ISSN. Se publica de forma anual en el sitio web de la Universidad de Alicante (http://web.ua.es/es/dama/) y en su repositorio (RUA). Los artículos publicados son descargables en formato PDF.

\section{Consejo de Redacción}

Directores (Coordinadores del Máster)

Carolina Doménech Belda

Fernando Prados Martínez

\section{Secretaria de Edición}

Julia Sarabia Bautista

\section{Vocales}

Los miembros de la Comisión Académica del Máster Universitario en Arqueología Profesional y Gestión del Patrimonio (http://dprha.ua.es/es/magip/comision-academica.html)

\section{Edita}

Máster Universitario en Arqueología Profesional y Gestión Integral del Patrimonio Departamento de Prehistoria, Arqueología, Historia Antigua, Filología Griega y Filología Latina

Facultad de Filosofía y Letras II

Universidad de Alicante

Ctra San Vicente del Raspeig s/n

E-03690 San Vicente del Raspeig (Alicante)

Web:http://dprha.ua.es

Teléfono: (+34) 965903663

Fax: (+34) 965903823

E-mail: revista.dama@ua.es

\section{ISSN}

$2530-2345$

\section{Portada}

Modelo fotogramétrico de un hypocaustum romano realizado por Ana Charquero 
EDITORIAL

Coordinación del máster

ENTREVISTA A SOLVEIG NORDSTRÖM: UNA MIRADA HACIA EL PASADO DE LA ESCUERA

Raúl Berenguer González ..

\section{ARQUEOLOGÍA Y MÉTODO}

EL ESTUDIO DE LOS MATERIALES CONSTRUCTIVOS DE TIERRA DEL CABEZO DEL POLOVAR (VILLENA, ALICANTE): APORTACIÓN A LAS FORMAS CONSTRUCTIVAS DE DOS PEQUEÑAS EDIFICACIONES CAMPESINAS DE LA EDAD DEL BRONCE EN EL LEVANTE PENINSULAR

María Pastor Quiles

VIVIENDAS POSTALAYÓTICAS: UNA APROXIMACIÓN A LOS ESPACIOS DOMÉSTICOS EN EL ARCHIPIÉLAGO BALEAR (550-123 ANE)

Octavio Torres Gomáriz

LAS FLOTAS DE GUARNICIÓN ROMANA EN LAS COSTAS DE HISPANIA A PARTIR DE LAS FUENTES EPIGRÁFICAS

Sergio Lledó Ramírez

UNA APROXIMACIÓN A LA RECONSTRUCCIÓN DEL PAISAJE HISTÓRICO: EL PROYECTO L'ALMISSERÀ Diana López Arroyo

NUEVAS PERSPECTIVAS PARA EL ESTUDIO ARQUEOLÓGICO DEL POBLAMIENTO RURAL MEDIEVAL EN ASPE (ALICANTE): HUERTAS Y ALQUERÍAS JUNTO AL RÍO TARAFA

Felipe Mejías López

ARQUEOLOGÍA DE LAS GUERRAS CARLISTAS

Iván Roldán Vergarachea

LA CERÁMICA DE USO ARQUITECTÓNICO EN NOVELDA: LA AZULEJERÍA DE FINALES DEL SIGLO XIX Y PRINCIPIOS DEL XX

Natalia Sala Pérez

PRÁCTICA Y USOS DE LA FOTOGRAMETRÍA DIGITAL EN ARQUEOLOGÍA

Ana $M^{a}$ Charquero Ballester.

\section{GESTIÓN Y PUESTA EN VALOR DEL PATRIMONIO}

ARQUEÓLOGOS CON DISCAPACIDAD. ARQUEOLOGÍA INCLUSIVA

Ana Samaniego Espinosa

"LES COVES DELS PESCADORS DE EL CAMPELLO": PROPUESTA DE RECUPERACIÓN, PUESTA EN VALOR Y USO PÚBLICO DE UN PATRIMONIO OLVIDADO

Ana Isabel Castro Carbonell .

LA COLONIA DE SANTA EULALIA. ESTUDIO Y PROPUESTA DE RECUPERACIÓN

Héctor de Arriba González

PROYECTO DE PUESTA EN VALOR DE LOS RESTOS DE LA GUERRA CIVIL EN LA CIUDAD DE ALICANTE

Leticia Victoria González Chouciño

ANTEPROYECTO MUSEOGRÁFICO DEL MUSEO DE HISTORIA DE SAX

Alberto Ochoa García

EL CONGRESO DE MÁSTER: UNA PROPUESTA DIDÁCTICA DEL MÁSTER DE ARQUEOLOGÍA DE LA UNIVERSIDAD DE ALICANTE

Ignasi Grau Mira, Sonia Gutiérrez Lloret, Carolina Doménech Belda, Julia Sarabia Bautista 



\title{
“LES COVES DELS PESCADORS DE EL CAMPELLO": PROPUESTA DE RECUPERACIÓN, PUESTA EN VALOR Y USO PÚBLICO DE UN PATRIMONIO OLVIDADO
}

\author{
Ana Isabel Castro Carbonell
}

\section{RESUMEN}

En este trabajo se realiza un estudio sobre el estado actual de les "Coves dels Pescadors" de El Campello (Alicante) en el que se incluye una puesta en valor que contribuye a reforzar la viabilidad de una intervención sobre el citado lugar para su rehabilitación. La prioridad de la estrategia patrimonial desarrollada gira en torno al reconocimiento de la importancia histórica y cultural de estos bienes en contraposición a su abandono secular, el análisis de su contexto y problemáticas, la aplicación de un plan de intervención y, por último, su reincorporación a la sociedad como espacio de uso destinado a la difusión de la cultura e identidad locales. Todo ello con el fin de propiciar marco ideal para la promoción del patrimonio etnológico y su inclusión plena en la sociedad contemporánea.

Palabras clave: cuevas, El Campello, patrimonio, pesca, recuperación.

\section{ABSTRACT}

This paper presents a study on the current state of their "Coves dels Pescadors" of El Campello (Alicante) in which an enhancement that contributes to strengthening the viability of an intervention on the said place for rehabilitation performed is included. The priority of the equity strategy developed revolves around the recognition of the historical and cultural importance of these goods as opposed to its secular abandonment, analysis and problem context, the implementation of an intervention plan, and finally, his reinstatement society as usable space for the dissemination of local culture and identity. The aim is to foster ideal for promoting ethnological heritage and their full inclusion in contemporary society framework.

Key Words: caves, El Campello, heritage, fishing, recovery. 


\section{INTRODUCCIÓN}

Las Cuevas de los Pescadores -"Les Coves de la Torre", "Les Coves del Clot de l'Illot", "Les Coves de la Mar" o, simplemente, "Les Coves" según la denominación local, se localizan en el municipio valenciano de El Campello ${ }^{1}$ (Alicante), al noroeste de la comarca del Alacantí. Lugar vinculado al mar desde tiempos remotos, el término municipal de esta población, por su geomorfología excepcional, admite una gran variedad de paisajes entre los que destacamos suaves playas de arena como la de Muchavista o la de Carrer de la Mar, calas de cantos y gravas como la de Amerador y, finalmente, acantilados. En la actualidad, el entorno portuario de El Campello ${ }^{2}$, espacio que afirma el contraste entre el litoral suave y el área agreste del frente marítimo, ha sido transformado y despojado de su función anterior quedando relegado al aprovechamiento terciario del

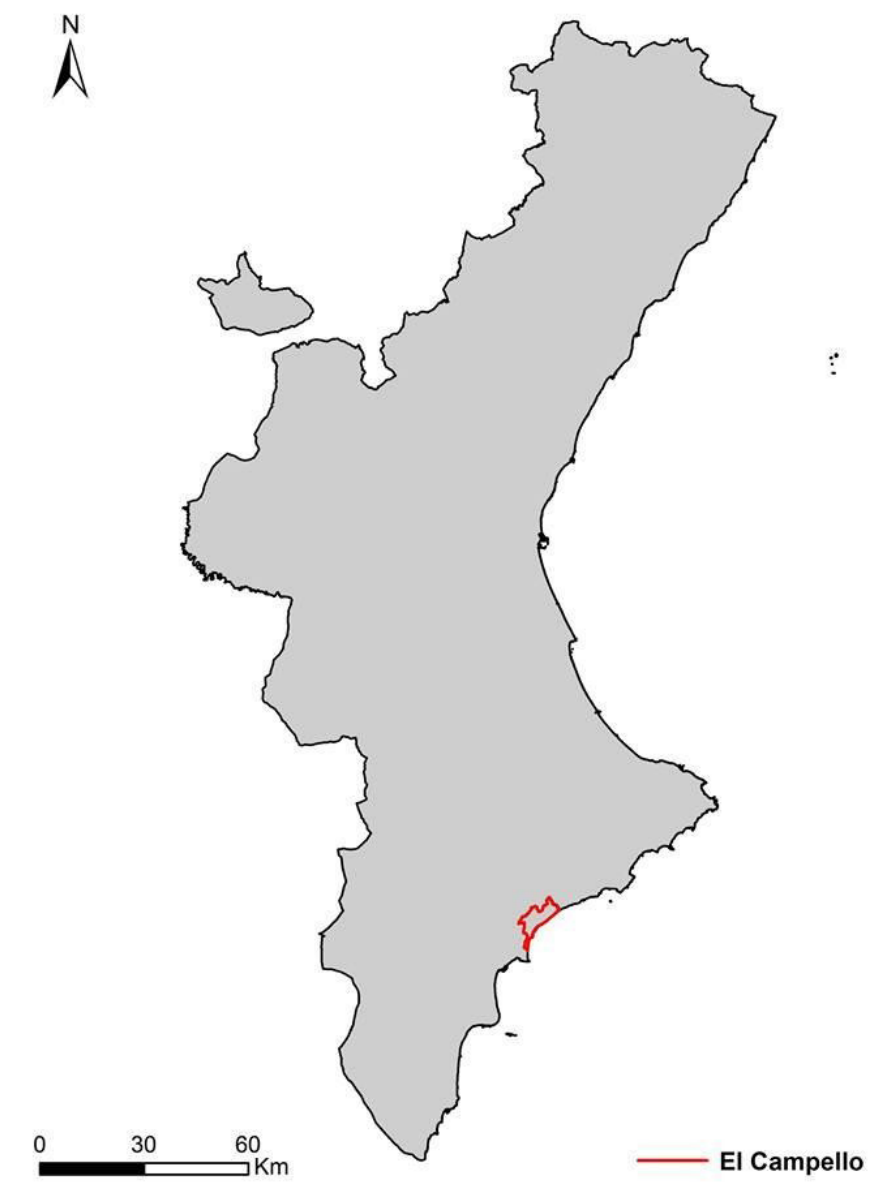
lugar como centro dedicado al recreo y a la práctica de deportes náuticos. El triunfo del sector servicios y de la urbanización ha llevado a una transformación y a una aceptación casi anecdótica de las realidades latentes durante los siglos XIX y XX al tiempo que ha acelerado la desmemoria de la ciudadanía.

En este contexto de transformación y antropización del medio, las antiguas Cuevas de los pescadores se convierten en uno de los principales elementos amenazados del patrimonio local. Atendiendo a esta problemática, en el presente plan de trabajo proponemos un modelo de intervención que busca recuperar y dotar de una nueva ética histórico-patrimonial al frente marítimo en cuestión. Asimismo, apuntalamos los ejes principales de una propuesta previa de proyecto $^{3}$ en la que se incluyen tanto los rasgos que tienen que ver con la caracterización morfológica y geológica de estos espacios como los modelos de gestión patrimonial pertinentes.

Fig. 1. Localización de El Campello (Eloy Poveda, 2014)

1 El municipio tiene una dimensión aproximada de 55,27 kilómetros cuadrados y se encuentra a una distancia aproximada de 13 kilómetros respecto a Alicante. Cuenta con 23 kilómetros de litoral y linda con la capital alicantina y con los pueblos de San Juan, Muchamiel, Busot, Aigües de Busot (Ferrer, 2006, 213; Olcina et al., 2009, p. 19).

2 En entorno urbano de El Campello, concretamente el área situada en el actual puerto deportivo donde están las instalaciones del club náutico (C.N El Campello), presenta un aspecto fuertemente alterado por la construcción y urbanización de la costa vinculada al aprovechamiento terciario y a la ocupación turística desmedida.

3 El presente artículo, es un avance de los resultados del trabajo de fin de máster desarrollado en el marco del máster de Arqueología Profesional y Gestión Integral del Patrimonio (2013-2014) bajo la dirección de la profesora Carolina Doménch Belda y de Antonio Espinosa Ruíz. Dicho proyecto fue defendido y evaluado en septiembre de 2014 ante un tribunal académico. 


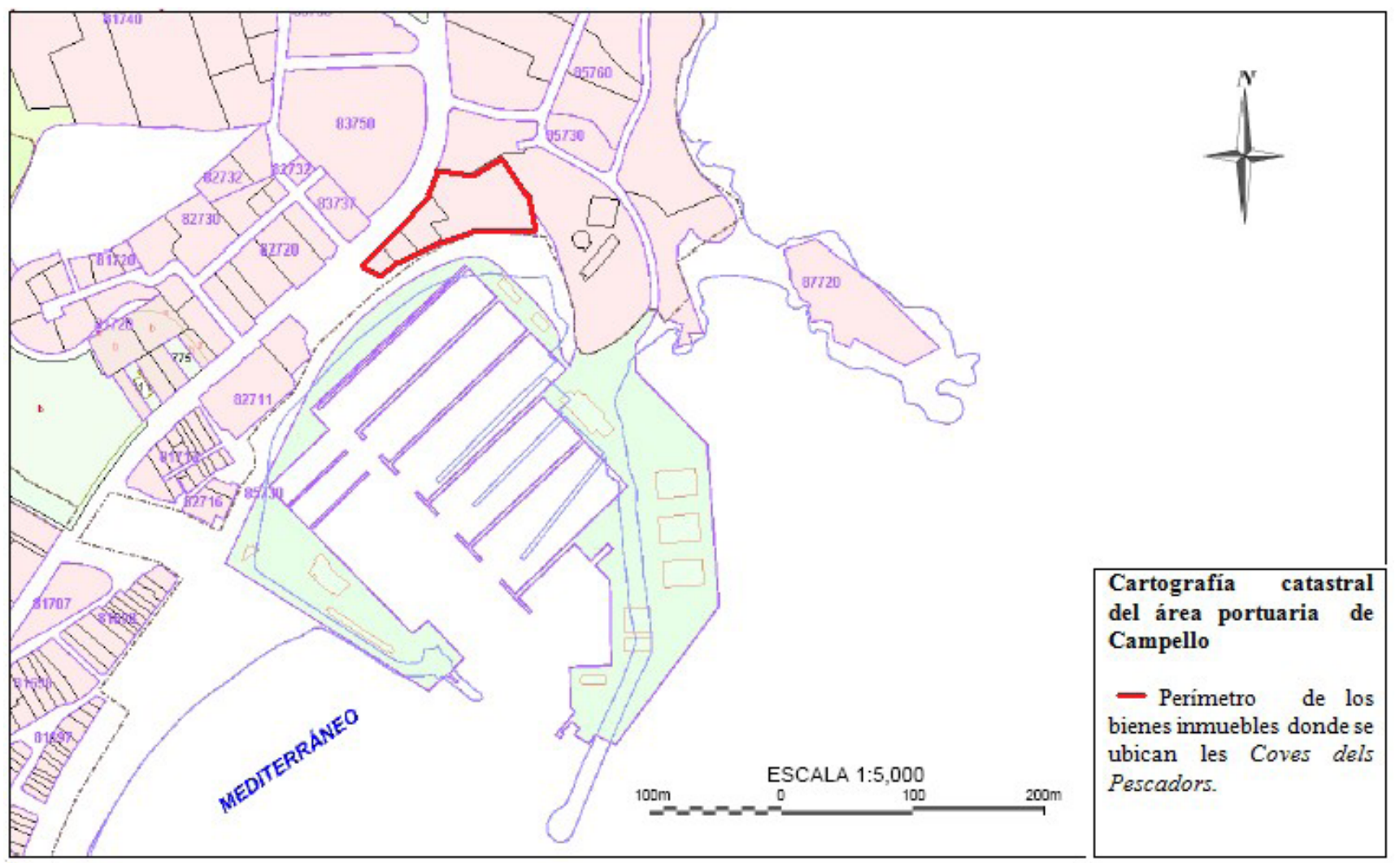

Fig.2. Ubicación de las cuatro parcelas catastrales donde se hallan las seis cuevas (elaboración propia).

\section{JUSTIFICACIÓN Y OBJETIVOS}

Nuestro objetivo general es elaborar una propuesta que suponga la recuperación, puesta en valor y uso público de "Les Coves dels Pescadors" que supere lo meramente testimonial y que contribuya a la creación de una estrategia de intervención patrimonial encaminada a la rehabilitación del lugar en su entorno.

La prioridad de dicha propuesta gira en torno al reconocimiento de "Les Coves" como patrimonio potencialmente recuperable tras una larga etapa de desuso y olvido, la aplicación de un plan de intervención y, por último, su reincorporación a la sociedad como espacio destinado a la difusión de la cultura e identidad de El Campello.

Junto a esta finalidad principal, proponemos: 1) Dar visibilidad a los citados elementos mediante la redacción de dos fichas de catalogación con sendas medidas de protección y conservación para su inclusión en el Catálogo de Bienes y Espacios Protegidos de Alicante y en el Catálogo de Bienes Protegibles de El Campello; 2) Analizar los valores patrimoniales que justifiquen la recuperación, conservación y puesta en valor de los bienes en su contexto; 3) Propiciar la creación de hojas de ruta que estimulen el conocimiento del patrimonio cultural, el enriquecimiento de la oferta cultural y turística así como la relación pasado-presente de la población.

\section{LOCALIZACIÓN, METODOLOGÍA Y TRATAMIENTO DE LA INFORMACIÓN}

La propuesta del presente trabajo, ha sido posible gracias a la confluencia de una serie de fuentes de carácter primario depositadas en organismos de ámbito local de El Campello y, en segundo lugar, por las aportaciones bibliográficas obtenidas de diferentes bibliotecas locales, repositorios y 
recursos web. En este sentido, debemos destacar el papel desempeñado por instituciones alicantinas de diversa índole comprometidas con la conservación del patrimonio local y la difusión de la cultura de la provincia. Entre los lugares a los que acudimos con más asiduidad se encuentran el Archivo Municipal del Campello (AMEC), el Archivo Histórico Provincial (AHP) y el Archivo de la Diputación de Alicante (ADA). Tampoco podemos dejar de mencionar los materiales que obtuvimos de la hemeroteca del Instituto de Cultura Juan Gil-Albert, de la Biblioteca Pública del Estado de Alicante y del Área de Planeamiento y Gestión Urbanística de El Campello. Igualmente significativos fueron los datos obtenidos del Portal de la Dirección General del Catastro. Por último, se emplearon fuentes orales, la viva voz de quienes de forma altruista y cordial colaboraron en la documentación del trabajo.

Debido al volumen de información recabada, hemos optado por diseñar un modelo de gestión que apostara por la inclusión a nivel local de "Les Coves" reconociendo como premisa que éstas no existen a efectos administrativos (no, al menos, desde un punto de vista patrimonial). Para corregir esta omisión, se ha revisado exhaustivamente tanto el Estudio del Paisaje del Plan General de Ordenación Urbana como el Catálogo de Bienes Protegibles de El Campello al tiempo que se ha optado por integrar el caso de estudio en el inventario preexistente analizando sus valores para, acto seguido, diseñar una ficha de Bien de Relevancia Local y un segundo documento siguiendo el modelo de la Dirección General de Patrimonio. Con ello, avanzamos un modelo de intervención compatible con las directrices de un anteproyecto para el área del puerto concebido desde el Museo Arqueológico de Alicante (MARQ).

\section{DESCRIPCIÓN DE LOS BIENES}

El conjunto estudiado se ubica en el Paraje de la Illeta s/n del puerto deportivo en las coordenadas 3825’57, 09” N (latitud) y 0 23' 8.10” W (longitud) de un promontorio rocoso donde antaño fue erigida una torre renacentista conocida como "Torre de la Illeta" y, junto a ella, un cuartel de carabineros (actual recinto de la Policía Local en fase de traslado). Las cuevas se hallan a 15 metros sobre el nivel del mar, en el lugar donde antiguamente había una cala natural protegida de los vientos de levante y de los temporales que esporádicamente azotan las costas alicantinas. Los materiales predominantes del entorno ${ }^{4}$ son de dos tipos: muestras del cuaternario (principalmente, cantos rodados cementados) y caliza miocena magnesiana pura (Piedecausa et al., 2011).

Las seis estancias se reparten a lo largo de la pendiente de la loma, están excavadas sobre materiales cuaternarios pleistocenos en un talud vertical (Piedecausa et al., 2011) y ocupan cuatro parcelas catastrales con una superficie total ${ }^{5} \mathrm{de} 8.543 \mathrm{~m}^{2}$. Su origen es confuso, pues no existe un testimonio que permita fecharlas de forma exacta, ni tampoco material arqueológico fiable que nos proporcione una cronología más allá de un amplio paréntesis que recorre la edad moderna y la época contemporánea. A pesar de ello, tenemos constancia de su uso como espacio de paso y de almacenamiento de aperos de las embarcaciones, almacén de pescado de la lonja y, más recientemente, lugar de vivienda. ${ }^{6}$

Los paralelos con otras cuevas de la provincia de Alicante (costeras y terrestres) nos han permitido categorizarlas dentro de la tipología de los refugios excavados ex novo que sin llegar a corresponderse con la propia de las oquedades contempladas dentro del denominado "hábitat troglodita", comparten rasgos con ellas. El caso podría interpretarse como un tipo de asentamiento en ladera abancalada. Esta

4 Tal y como confirmaron los difractogramas realizados durante el muestreo llevado a cabo por el Departamento de Construcciones Arquitectónicas de la Universidad de Alicante en el año 2011.

5 Este dato ha sido obtenido utilizando la aplicación de medida de superficies que ofrece el visor de parcelas agrícolas (Sigpac) del Ministerio de Agricultura, Alimentación y Pesca (http://sigpac.mapa.es/fega/visor/).

6 Tal y como confirmaron tanto las fuentes escritas -especialmente la obra de Rafael Altamira titulada "Cuentos de Levante" (1895) y el poemario de Encarnació Giner i Paradi “A la vora del mar" (1990)-, como los testimonios orales. 


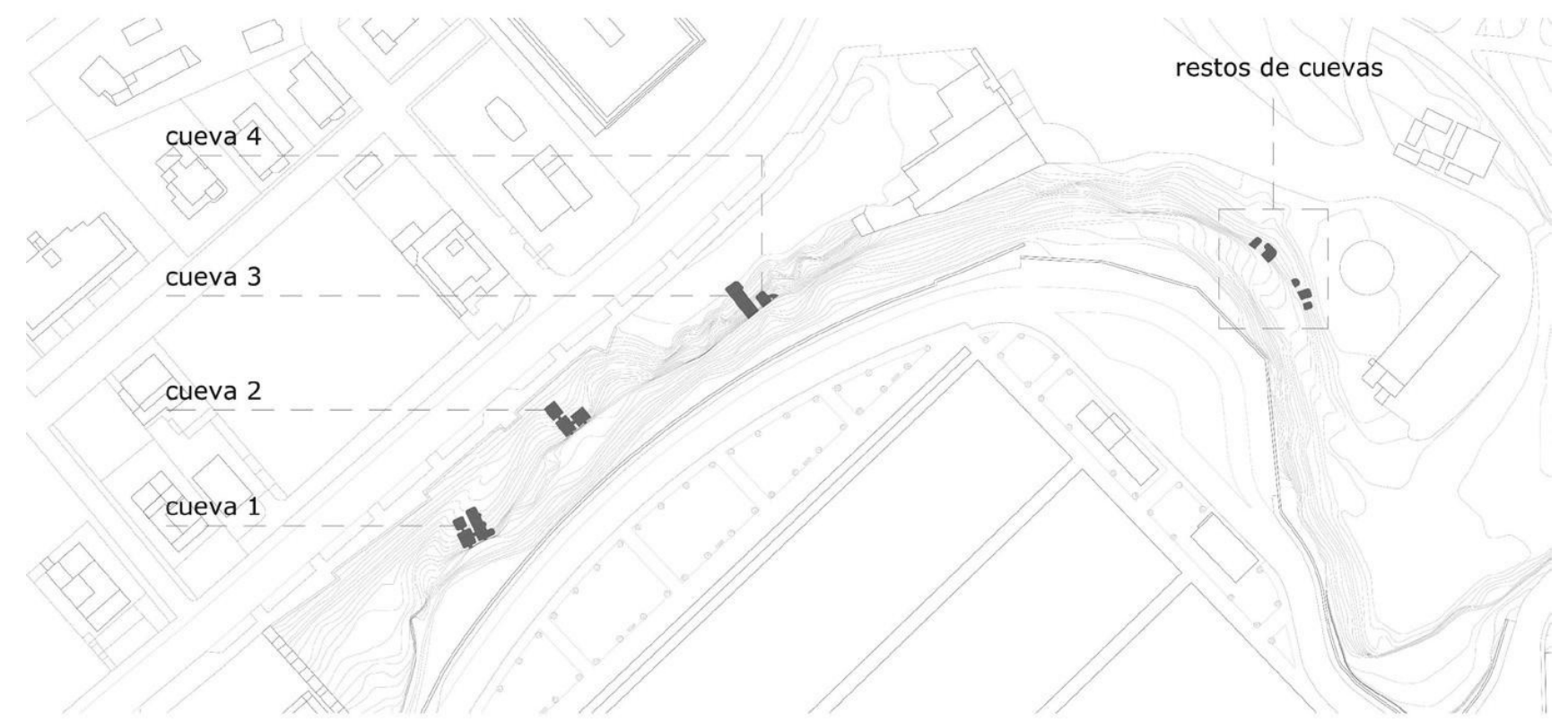

Fig.3. Ubicación de las cuevas en el promontorio del Clot de l'Illot (Piedecausa, et alii, 2011). Los restos de cuevas equivalen a las estructuras 5 y 6.

circunstancia se da cuando el terreno alberga bancos dolomíticos escalonados con una superficie tan ancha y resistente que permite formar techos y suelos. La litología crea las condiciones idóneas para la construcción de espacios enterrados al presentar rellenos margo-arenosos fácilmente excavables (Aranda, 1986: 35; García y López, 2000, p. 38). Morfológicamente, se componen de una fachada de tamaño modesto (entre 2,5 y 3 m de altura) con puertas y ventanas de tendencia rectangular. Las jambas suelen estar recubiertas de mortero de cemento o de cal y se acomodan al talud vertical sobre el que están (motivo por el cual no son exactamente rectas). En segundo lugar, identificamos una serie de construcciones anexas (apreciables en las Cuevas 2 y 3), donde las modificaciones posteriores han generado paredes adosadas de ladrillo o cemento "portland". Respecto a las paredes y los suelos, como en la mayoría de hábitats enterrados, las superficies interiores y exteriores están cubiertas de un enlucido de yeso, aunque no descartamos que durante la etapa de acondicionamiento como viviendas se aplicara pintura plástica. En cuanto a los pavimentos, por el momento resulta imposible determinar cómo eran por la gran cantidad de escombros y arena que hay dentro, pero no resulta descabellado pensar que también estuvieran encalados (Piedecausa et al., 2011).
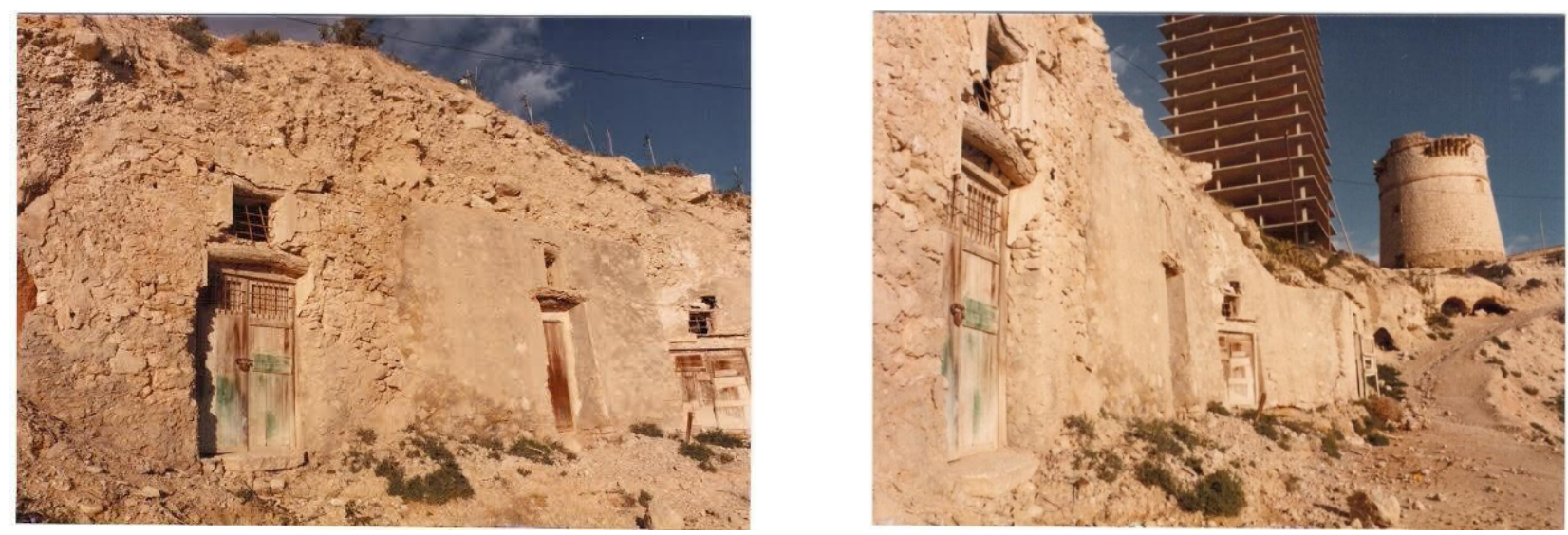

Fig.4. Izquierda: Aspecto que presentaban "Les Coves" en el año 1985. Al fondo la torre vigía renacentista y el edificio que finalmente fue detonado Año 1985; derecha: Detalle de fachada. Se aprecia la existencia de lucernarios (fotografías cedidas por gentileza de Adoración Martínez Carmona y Feliciana Sala Sellés). 


\subsection{Cueva 1}

La primera de las cuevas se encuentra a 3,5 metros respecto al paseo del puerto y presenta tres estancias excavadas en el terreno que comunican entre sí y una entrada con un enfoscado de cemento aplicado durante una intervención posterior. La sala que da acceso tiene forma rectangular y mide 7 , 5 metros de longitud, 2,6 metros de ancho y 2,6 metros de altura.

La estancia principal dinamiza un espacio contiguo al que se accede por una entrada longitudinal que iguala su anchura pero que no supera la longitud de 2,6 metros. Esta segunda sala de 3,6 metros de profundidad con su correspondiente salida al exterior se desarrolla hacia el interior dando lugar a una habitación cuadrangular con unas medidas aproximadas de 3,6 metros de largo y 2, 6 metros de ancho. La altura total de este segundo espacio es de 2,3 metros (Piedecausa et al., 2011).

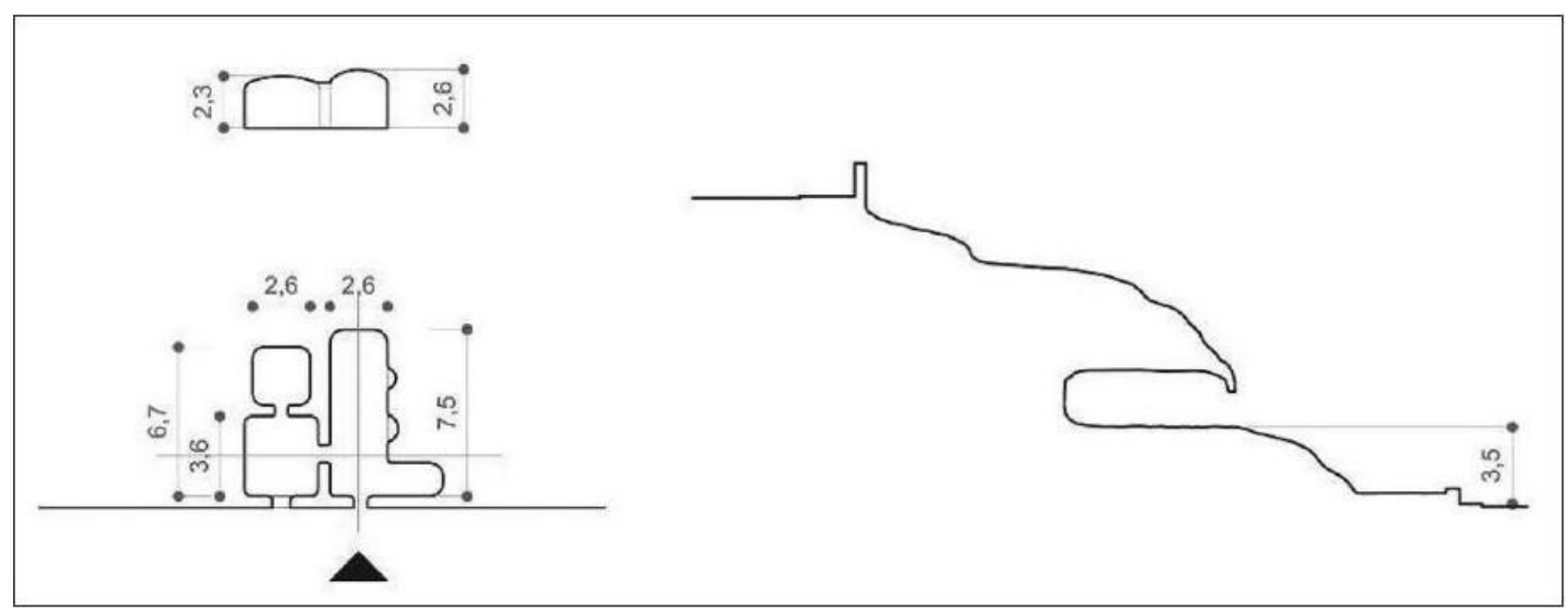

Fig. 5. Dimensiones en planta y sección transversal de la Cueva 1 (Piedecausa et al., 2011)

\subsection{Cueva 2}

La Cueva 2 tiene una forma similar a la Cueva 1. Se encuentra a 5,5 metros de altura respecto al paseo. La dependencia principal que da acceso al espacio excavado tan sólo mide 4 metros de largo por 3 de ancho y se desarrolla hacia el interior, al contrario que en la Cueva 1. La sala que comunica longitudinalmente con ésta comparte esta anchura pero es ligeramente más reducida que la anterior. El acceso transversal es similar al de la primera cueva y da paso a una dependencia de 3,5 metros de longitud por 3 metros de ancho. En la segunda estancia, a diferencia de la primera, las paredes conservan restos del encalado que se aplicó sobre ellas (Piedecausa et al., 2011).

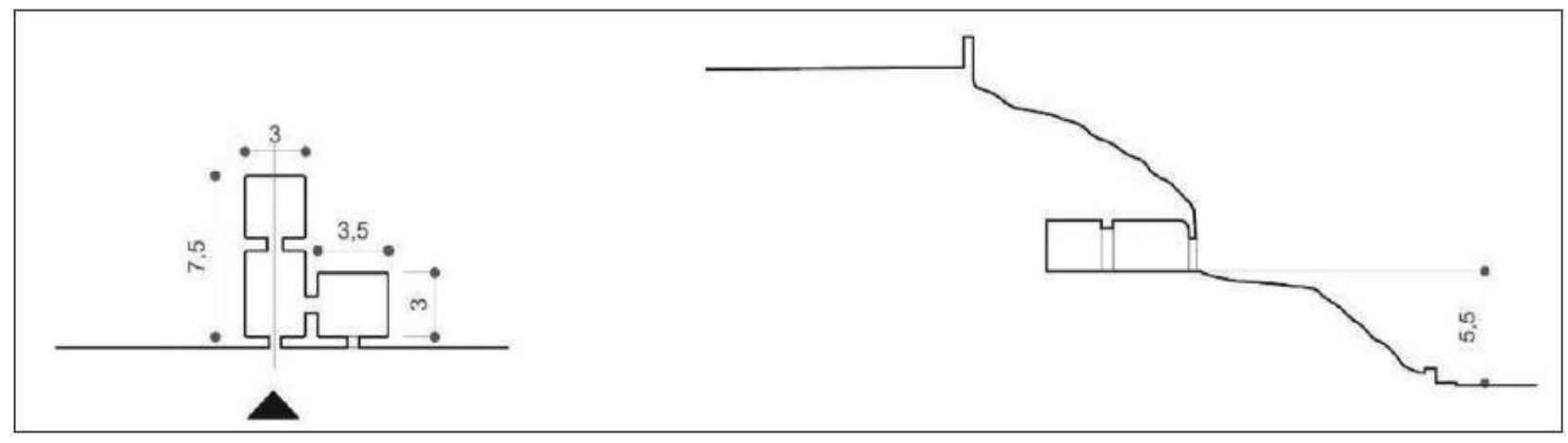

Fig. 6. Dimensiones en planta y sección transversal de la Cueva 2 (Piedecausa et al., 2011). 


\subsection{Cueva 3}

La Cueva 3, ubicada a 6,6 metros sobre el paseo, sólo presenta una pequeña dependencia alargada sin revestimientos artificiales aparentes. Tiene unas dimensiones más bien modestas (8 metros de longitud y tres metros de ancho en su pasillo). En la zona más profunda se percibe una pequeña ampliación de apenas unos centímetros que le da mayor anchura (Piedecausa et al., 2011).

Es destacable la capa cenicienta creada por un fuego que recubre gran parte de sus paredes. Este hecho justifica la inexistencia del revestimiento de yeso habitual, que a grandes temperaturas reacciona y termina convirtiéndose en anhidrita (Piedecausa et al., 2011, p. 160).

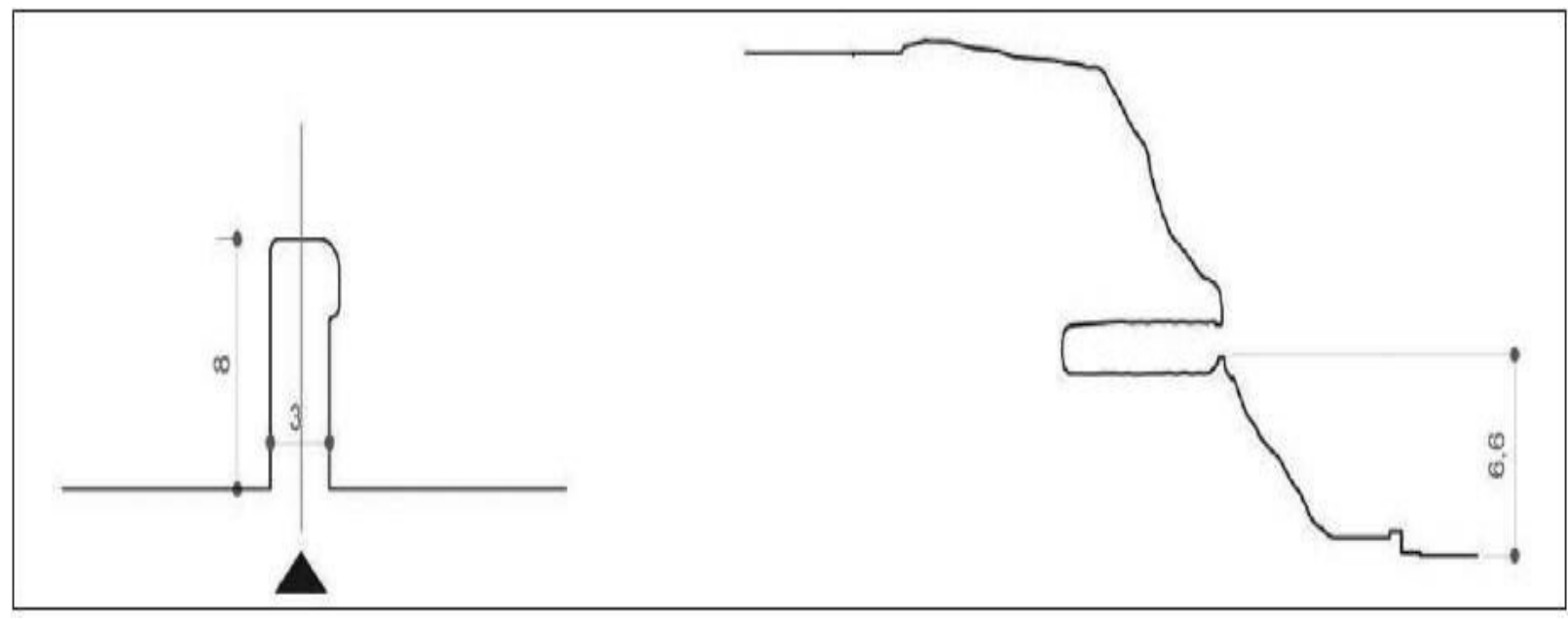

Fig. 7. Dimensiones en planta y sección transversal de la Cueva 3 (Piedecausa et al., 2011).

\subsection{Cueva 4}

La cuarta cueva se halla cerca de la anterior, separada por escasos metros, y al igual que Cueva 3 carece de revestimiento alguno. En realidad, se trata de dos dependencias relacionadas entre sí por un estrecho pasillo, una de un tamaño especialmente pequeño. Basándonos en su cercanía parece probable que desde un punto de vista funcional se asociaran al uso de la tercera cueva. La escasa altura del techo hace especialmente incómodo el acceso y la movilidad tanto en la habitación más grande como en el giro que hace el pasillo hacia salita siguiente (Piedecausa et al., 2011).

\subsection{Cuevas 5 y 6}

Las últimas dos cuevas pueden clasificarse en un único grupo por su tamaño reducido y por su aspecto parcialmente ruinoso. Tienen una forma abrigada, por lo que sería más correcto referirnos a ellas como oquedades en el terreno. Presentan un estado de conservación malo y presentan un revestimiento que se ha desprendido en la mayor parte de sus paredes (Piedecausa et al., 2011). Se hallan indisolublemente unidas a la imagen del restaurante que hay sobre ellas y que tiene como nombre "La Cova".

\section{DIAGNÓSTICO Y CONSERVACIÓN}

Las deformaciones más evidentes debieron generarse por cuestiones físicas tales como el aerosol marino, la erosión atmosférica o la suciedad unidas a la colonización vegetal apreciable en todo el corte vertical. Dichas patologías vienen acompañadas de un alto porcentaje de humedad por capilaridad, condensaciones y filtraciones que suele ser muy habitual en los refugios similares y supone un problema serio, ya que ésta al migrar hacia la zona interior de las cuevas disuelve el 
material cementante y le hace perder resistencia. La consecuencia inmediata es la aparición de costras superficiales de forma abombada (García y López, 2000, pp. 81-84).

En cuanto a las de lesiones mecánicas, la más habitual es la fragmentación con la disgregación de la cara superior labrada de los bloques o ladrillos agregados y la pérdida parcial o total de la argamasa de barro y cal en el exterior. El yeso y en menor grado el cemento son los materiales culpables de la aparición de sales solubles, patología habitual en las construcciones cercanas al mar (Piedecausa et al., 2011, p. 162). Es habitual que estos males provoquen picados en el material y poros que permiten su absorción por capilaridad (higroscopicidad).

Debido al cúmulo de factores y a las inclemencias meteorológicas se han hallado fases de nueva formación como sucede con los sulfatos y cloruros de sodio. Dichos elementos también han contribuido al desprendimiento del encalado con el que originalmente se revistieron las paredes de, al menos, las cuevas 1, 2, 3 y 4. La consecuencia final es el craquelado, desprendimiento o rotura apreciable en innumerables grietas y fisuras.

Dentro de las lesiones mecánicas, la destrucción causada tras el abandono de los refugios por expolios y actos vandálicos también es destacable. En todas las cuevas de mayor tamaño hay roturas intencionadas del cegado de las puertas y ventanas, grafiti y grandes acumulaciones de desperdicios (mobiliario roto, basuras orgánicas, etc.). A estos agentes cabe sumar las afecciones ocasionadas por diferentes plagas de insectos, arácnidos, roedores, etc.

Las lesiones químicas, por su parte, aparecen asociadas a manchas o eflorescencias superficiales, organismos vivos, depósitos y costras.

\section{ANÁLISIS PREVIO}

\subsection{Identificación de los valores patrimoniales}

"Les Coves dels Pescadors" atesoran las tres asignaciones básicas ${ }^{7}$ que contemplan Josep Ballart, Josep María Fullola y Maㅡ dels Àngels Petit (1996).

1.- Valor de uso. Se trata de un aspecto inmaterial que remite al sentido funcional o estrictamente utilitario de una determinada creación, esto es, a la cualidad del producto para satisfacer una necesidad humana. Este atributo es el que se manifiesta con mayor intensidad dado que las cuevas, como hemos visto, no tuvieron una utilidad única.

2.- Valor formal. Según Ballart (1997, p. 76) “el valor formal de un objeto se incrementa siempre en relación a la calidad del trabajo que incorpora". El caso estudiado es un ejemplo extraordinario, dado que constituye la mayor acumulación por zona de cuevas de pescadores de la provincia de Alicante excavadas, parcialmente, sobre una pared rocosa.

3.- Valor simbólico-significativo. La zona en cuestión sigue presente en el imaginario popular y, en la actualidad, continúa siendo un punto de reunión para los locales y una referencia visual clara para acceder a las instalaciones del puerto o al propio paseo marítimo. El hito en cuestión es, junto al icono de la torre, uno de los reclamos visuales más característicos del Paraje de la Illeta.

7 No podemos perder de vista que la asignación de un determinado valor cambia con el tiempo. No es el mismo valor que tenían antes que el que le damos actualmente. Puede suceder que un objeto quede desprovisto de su significado primigenio (Ballart, 1997, p. 62). 
Además de estos méritos que son lo más sobresalientes reconocemos otros de carácter secundario: el valor de antigüedad (porque su origen se remonta a varias generaciones atrás en el tiempo); el valor gremial, por constituir la memoria de los oficios del mar y, en tercer lugar, y no por ello menos importante, el valor memorístico o emocional ligado a las pulsiones, sentimientos y recuerdos de aquellas personas con vínculos afectivos o vivencias relacionadas con la etapa previa al abandono de los bienes. Tampoco podemos pasar por alto el valor medioambiental que poseen por hallarse en un paisaje con elementos naturales y culturales extraordinarios como parte de un contexto mayor de gran singularidad y belleza.

Por ello, toda información que se desprende de cada uno de los citados valores es por sí misma un activo potencialmente útil para legitimar su recuperación y uso por parte de la sociedad moderna.

\subsection{Tres vías para el reconocimiento legal de los bienes}

La carrera hacia la consecución legal de los bienes pasa, necesariamente, por tres estadios perfectamente complementarios.

\section{a) Inclusión en el Catálogo de Bienes Protegibles de El Campello}

Todos los elementos que se encuentran amparados legalmente en el marco del Catálogo de Bienes y Espacios protegidos de El Campello forman parte del Plan General según lo determinado por el artículo 77 de la Ley Urbanística Valenciana, desarrollado por el art. 139.3 del ROGTU. El texto toma como modelo el Inventario General de Yacimientos Arqueológicos de la Comunidad Valenciana y la revisión de la anterior normativa urbanística (Catálogo de Bienes Protegibles de El Campello, 2010). Si aplicamos la media por interés histórico y artístico siguiendo los baremos establecidos obtenemos una puntuación que determina el grado de protección definitivo en armonía con la valoración del resto de bienes del inventario local. En el documento en cuestión existen tres categorías cada una con sus respectivos criterios de actuación y consideraciones oportunas.

\begin{tabular}{|c|c|l|c|}
\hline Categoría & Grado & Nivel de protección & Interés \\
\hline Categoría 1 & 1 & Protección Integral & Alto \\
\hline Categoría 2 & 2 & Protección Parcial & Medio \\
\hline Categoría 3 & 3 & Protección Ambiental & Bajo \\
\hline
\end{tabular}

Fig. 8. Categorías y grados de protección establecidos en el Catálogo de Bienes Protegibles de El Campello (elaboración propia).

Si aplicamos la media por interés histórico y artístico siguiendo los baremos establecidos obtenemos que las cuevas se adhieren al Grado 2. Protección Parcial al obtener una puntuación de 1,5. Su consideración queda sujeta a unas normas preceptivas del Catálogo de Bienes Protegibles de El Campello (2010, p. 6) en las que se detalla que una vez obtenido el nivel de protección parcial, se protegerán las construcciones o recintos que por su valor histórico o artístico deban ser conservados, al menos en parte, preservando los elementos definitorios de su estructura arquitectónica o espacial y los que presente valor intrínseco autorizándose las siguientes intervenciones: a) las obras 
congruentes con los valores catalogados 8 b) la demolición de algunos de los elementos señalados cuando no gocen de una protección específica por el Catálogo, cuando sean de escaso valor definitorio del conjunto o comporten problemas de conservación del inmueble. Por ello, vemos esta acción altamente satisfactoria.

\section{b) Ampliación del estudio del Paisaje del Plan General de Ordenación Urbana de El Campello}

El Estudio del Paisaje del Plan General de Ordenación Urbana de El Campello ${ }^{9}$, enmarcado en las competencias del trabajo de los Servicios de Planeamiento y de Gestión Urbanística del Área de Territorio y vivienda del Ayuntamiento, fue un documento en el que se fijó una normativa para supervisar cualquier incidencia territorial sobre el paisaje del término municipal. En la actualidad, el Plan General se encuentra invalidado por la ausencia de un estudio económico financiero que respaldara una expropiación de un restaurante ${ }^{10}$ según la sentencia emitida por la sección quinta de la Sala de lo Contencioso-Administrativo del Tribunal Superior de Justicia valenciano (TSJCV). Con todo, en caso de reformularse o refundirse en los términos correctos consideramos que tendría un valor indispensable en el proyecto dado que se podrían incluir y corregir aspectos relacionados directamente con los bienes que venimos estudiando. El valor del plan estriba en que recoge y cataloga todos los elementos (naturales o antrópicos) que componen el valor paisajístico del municipio. También establece las directrices definitorias de la estrategia de evolución urbana y de ocupación del territorio de la población (DEUT). Una de las directrices definitorias más interesantes es la relativa a la sostenibilidad y al diseño de Planes Especiales que sirvan de nexo con un futuro Plan de Acción Territorial del Litoral con el objetivo "de mejorar la homogeneidad de la fachada marítima, favorecer el uso y disfrute del Dominio Público Marítimo-Terrestre” (Plan General, 2011). Dicho valor, en las versiones que le anteceden, se establecía a partir del reconocimiento de unas categorías de calidad visual para las Unidades del Paisaje y Recursos Paisajísticos que dependían de las características ambientales, sociales, culturales y visuales.

El área del casco urbano y del puerto, comprendida dentro de la "UPL-3: El Campello", aunque en el antiguo PGOU tiene una calidad visual media y una fragilidad visual media-baja, ve incrementados sus valores por los elementos patrimoniales de la zona (las casas de principios de siglo de la Calle Mayor, la Ermita del Carmen, la Cantera del Pla d'en Sarrió, la Illeta dels Banyets, la Torre Vigía y el Convento de los Mercedarios). Todas estas alusiones son importantes porque desde hace tiempo contribuyen a la definición de los objetivos de la Calidad Paisajística para el área entre los cuales se indica la necesidad de "una mejora del carácter existente a partir de la introducción de nuevos elementos o la gestión de los existentes" (Estudio del Paisaje del Plan General de Ordenación Urbana de El Campello, 2007, p. 48). De este modo, aprovechando la reformulación del Plan General y de los estudios que dependen de él-Les Coves se podrían introducir en el Catálogo del Paisaje del propio Plan General, en caso de realizarse, con una alusión a "Les Coves dels Pescadors" en la "Ficha nํ․-Recurso Paisajístico- Paseo del Puerto". Hasta la fecha, y desde 2005, los objetivos de la ficha sólo se expresaba "la mejora del carácter mediante la mejora de elementos degradados" (Estudio del Paisaje del Plan General de Ordenación Urbana de El Campello, 2007, p. 52). En esta recomendación probablemente se refiere a las cuevas sin llegar a nombrarlas directamente porque durante la

8 Siempre que mantengan los elementos definitorios de la estructura arquitectónica o espacial tales como los espacios libres, alturas y forjados, jerarquización de volúmenes interiores, escaleras principales, el zaguán si lo hubiera, la fachada y demás elementos propios.

9 Aprobado por la Comisión Territorial de Urbanismo en fecha de 1 de abril de 2011 habiendo sido publicado en el BOP no 89-1, de 12 de mayo de 2011.

10 Según la sentencia relativa al recurso de casación del restaurante "Seis Perlas" (http://www.diarioinformacion.com/ alacanti/2016/04/08/supremo-anula-plan-general campello/1747752.html) 
consulta preliminar del Catálogo de Bienes Protegibles el equipo de redacción del Plan no advirtió ninguna categoría de protección que pesara sobre ellas y, por lo tanto, las eximió de cualquier valor dentro del recurso paisajístico "Paseo del Puerto". Como parte de esa problemática causada por la invisibilidad de las cuevas para la administración municipal, creemos altamente recomendable que se efectué una declaración de B.R.L en función de lo establecido anteriormente y que se aporte una referencia oportuna que garantice la conservación de la zona con todos y cada uno de sus elementos paisajísticos, incluyéndose el camino tradicional del Clot de l'Illot (hoy paseo del puerto) que aparecería en el "Capítulo Cuarto: Caminos tradicionales" del Plan General (en caso de haber continuado en vigor).

\section{c) Propuestas para la creación de fichas de catalogación}

Por último, una vez superada la evaluación previa a la que están sujetos los elementos patrimoniales de El Campello aconsejamos la creación de dos modelos de fichas que emulen la estructura de los recursos recogidos en el catálogo y en el inventario de la Dirección General del Patrimonio Cultural. Todo ello con arreglo a la Ley 5/2007, de 9 de febrero, de modificación de la Ley 4/1998, de 11 de junio, del Patrimonio Cultural Valenciano, «BOE» núm. 71, de 23 de marzo de 2007 y la normativa municipal (actualizada). Esta acción promovería no sólo el reconocimiento de "Les Coves dels Pescadors" dentro de una categoría legal (Bien de Relevancia Local) sino que también afianzaría las bases para incoar un futuro régimen de intervención.

\section{MODELOS DE PUESTA EN VALOR Y USO PÚBLICO}

En este punto, consideramos imprescindible rememorar aquellos proyectos previos que mostraron interés por el conjunto y, a partir de ellos, catapultarnos hacia la proyección de su recuperación total y uso público.

\subsection{Trabajos previos: el proyecto del DAC de la Universidad de Alicante}

Un primer intento para la recuperación de "Les Coves" se llevó a cabo en el año 2011 de forma ajena al proyecto del MARQ desde el Departamento de Construcciones Arquitectónicas de la Universidad de Alicante en colaboración con la asociación local Museo-Historia de El Campello (AMH). Fue planteado a partir de una parte del proyecto final de la alumna Lorena González Ciller en 2010 el que se proyectaba la rehabilitación de tres de las cavidades (las de mayor tamaño).

El estudio incluía los dibujos de las cuevas y de sus estancias junto a un análisis sedimentológico de los materiales naturales y del revestimiento arquitectónico de la entrada de cada uno de los espacios. Asimismo, también hacía un planteamiento para la puesta en valor. El mérito del trabajo es inmensurable y nos ha servido como material de apoyo constante, sin embargo, el proyecto carece de un análisis desde un punto de vista de la gestión histórico-patrimonial. Por ello, creemos altamente aconsejable aportar una visión complementaria que, desde la propuesta teórica que exponemos, se efectúe desde la Diputación de Alicante para integrar los bienes dentro de un discurso museográfico mayor que tenga en cuenta su entorno y que, a su vez, incremente la posibilidad de una puesta en valor con una financiación que asegure su recuperación y mantenimiento.

\subsection{Actualidad y perspectivas de futuro: el Centro de Interpretación del Paisaje Cultural de la Illeta}

El peso que otorgamos en el presente trabajo al paisaje no es inocente. Como advertíamos inicialmente perseguimos gestionar de forma eficaz los recursos técnicos económicos, materiales y humanos para garantizar la conservación preventiva del futuro B.R.L. Para convertir esta idea en una realidad creemos oportuno integrar el conjunto de oquedades en el discurso museográfico del Paisaje 
Cultural de la Illeta propuesto por el MARQ. Esta opción se justifica en el propio interés demostrado por la Diputación de Alicante en llevar a cabo un proyecto museográfico en el antiguo "Clot de l'Illot" y en el entorno inmediato del yacimiento de la Illeta dels Banyets después de que la zona pasara a formar parte del Plan Nacional del Paisaje Cultural mediante un capítulo exclusivo en el libro "100 Paisajes Culturales en España" (2015) contextualizado dentro de los trabajos llevados a cabo por el Plan Nacional del Paisaje Cultural. ${ }^{11}$

El Centro de Interpretación del Paisaje Cultural a cuyo anteproyecto arquitectónico y expositivo no hemos podido acceder por encontrarse en fase de revisión, pretende dar a la zona una visión de conjunto en la que se inserten elementos culturales, medioambientales y patrimoniales desde la perspectiva del desarrollo sostenible. Según la información disponible hasta el momento en la publicación "La Illeta dels Banyets. Un pont del passat al futur" (VV.AA., 2013, p. 62) sus contenidos estarían dedicados a los alfares ibéricos, la torre vigía, una aljibe y el propio medio marino y litoral mostrando, además, soluciones a cuestiones que distorsionan el entorno o dificultan el acceso al yacimiento. A estos bienes se sumaría el hallazgo de una necrópolis ibérica documentada tras los sondeos realizados recientemente por la empresa arqueológica Estrats Treballs d'Arqueologia S.L. La iniciativa en cuestión plantea actuar como polo de atracción del turismo cultural, dinamizando los valores de la zona de "la Illeta" y coordinando las campañas de promoción, difusión, didáctica y sensibilización ciudadana oportunas. Resulta especialmente ilustrativa porque avanza un objetivo futuro que tomará la estructura habitual de un proyecto museográfico en el que constarán las claves funcionales, formales, constructivas y económicas (VV.AA, 2005, p. 29) para la realización del centro un centro de interpretación o aula cultural tras el desmantelamiento del cuartel de la benemérita.

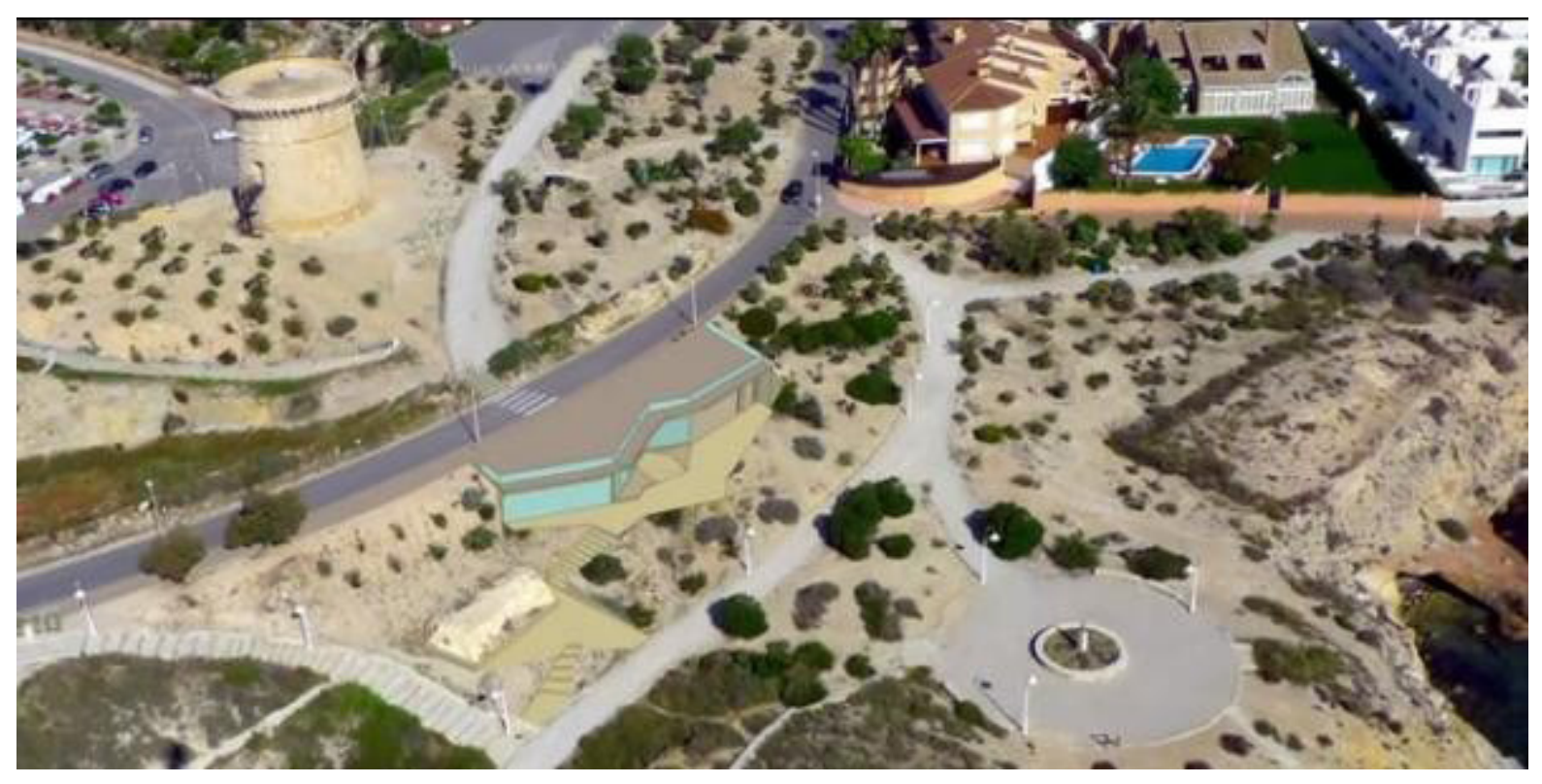

Fig.9. Ubicación hipotética del Centro de Interpretación del Paraje Cultural de la Illeta. Captura de imagen del video promocional "La Illeta: un puente entre culturas". (http://vimeo.com/70770206)

Por este motivo, la iniciativa que planteamos para la puesta en valor, lejos de constituir un modelo de gestión centrado exclusivamente en los bienes que hemos documentado, pretende formar parte del proyecto del museo arqueológico provincial descrito. Con ello, buscamos recuperar un patrimonio olvidado y ponerlo en conexión con el marco físico que de por sí también posee valores suficientes para ser protegido y presentado a la ciudadanía.

11 Ver: http://www.marqalicante.com/Noticias/es/El-Ministero-de-Cultura-incluye-la-Illeta-dels-Banyets-y-su-entorno-entre-los-cien-paisajes-patrimoniales-de-Espana-N486.html 


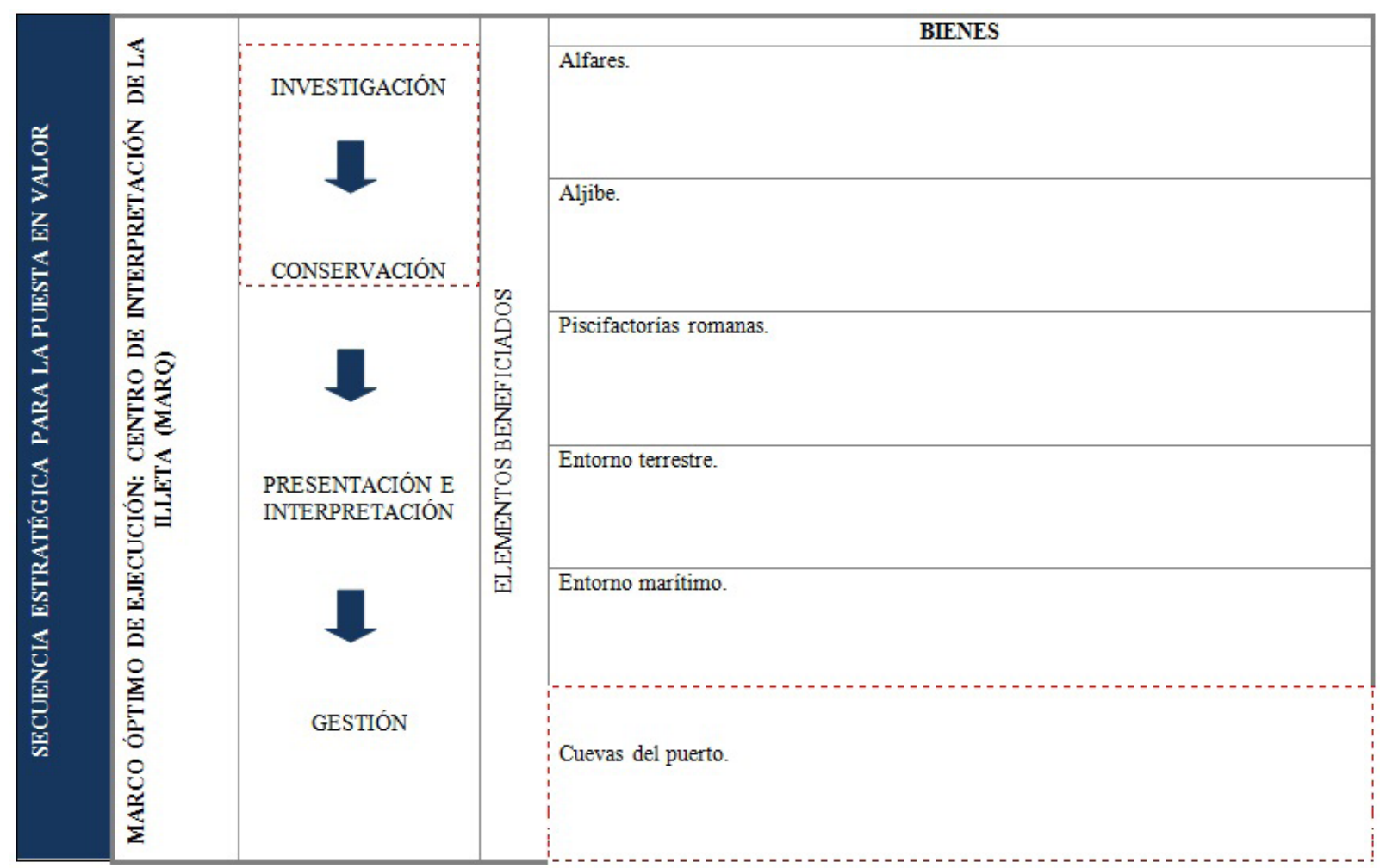

Fig.10. Secuenciaestratégicaparalapuestaenvalor. Enlínea discontinuaindicamosnuestraaportación hipotética dentro del proyecto museográfico mayor concebido desde el MARQ (elaboración propia).

\section{CONCLUSIONES}

La indefensión del patrimonio etnológico es, en la actualidad, uno de los aspectos que se suman a la cantidad de cuestiones con los que deben lidiar casi a diario los profesionales de la arqueología y de la museología. Las cuevas del "Clot de l'Illot" encajan en ese grupo heterogéneo de los bienes olvidados. Constituyen un legado precioso por ser los primeros refugios de la línea costera alicantina norte excavados parcialmente sobre una pared rocosa, la mayor acumulación de cavidades de esta naturaleza del ámbito espacial descrito y el más extraordinario conjunto de cuevas de pescadores toda la Costa Blanca. Son únicas tanto en número como por la proximidad que presentan unas respecto a otras y únicamente podrían compararse, y sólo parcialmente, con los refugios de la Cala Moraig de Benitachell. Sin embargo, han sido olvidadas por la administración local y por gran parte de la población y en la actualidad se encuentran en un estado ruinoso. La amplitud de posibilidades que existen para su puesta valor no arroja una única vía para su recuperación; ello nos obliga a elegir entre propuestas previamente exploradas (como el proyecto del Departamento de Construcciones Arquitectónicas de la UA) o nuevas, ya que probablemente no existe una única forma de gestionar el patrimonio y de cumplir con la promesa de devolverlo a la sociedad. Viéndolo desde una perspectiva histórica y patrimonial, la iniciativa esbozada por el MARQ para la creación del Centro de Interpretación del Paraje de la Illeta con la recuperación del "camí de Les Coves" nos parece especialmente interesante porque pone el acento en el paisaje, en las lecturas del paisaje, y fija la puesta en valor como una acción unitaria que debe dotar de coherencia a un espacio en el que también hay otros yacimientos emergentes y elementos que merece la pena conservar.

Por todo, el patrimonio etnológico no puede ser visto de ningún modo como un producto de consumo rápido. Tal y como hemos visto necesita ser transformado por un equipo profesional competente y devuelto a la ciudadanía como un elemento en el que pueda reconocerse de forma sostenida a lo largo del tiempo. 


\section{BIBLIOGRAFÍA}

Altamira y Crevea, R. (1895). Cuentos de Levante. MDS Books/Mediasat, Madrid, 2004.

Ballart Hernández, J. et al. (1996). El valor del patrimonio histórico, Complutum, Extra, 6, pp. 215-224.

García J.A. y López J.A. (2000). Las cuevas de Crevillente. Estudio y Catálogo Gráfico. Instituto Alicantino de Cultura Juan Gil Albert.

Giner i Parodi, E. (1990). A la vora de la mar. Ayuntamiento de El Campello.

Olcina M. et al. (2009). La Illeta dels Banyets. El Campello, Alicante. Épocas Ibérica y Romana I. Historia de la investigación y síntesis de las investigaciones recientes (2000-2003). Diputación de Alicante y Museo Arqueológico de Alicante, Alicante.

Piedecausa, B. et al. (2011). Recuperación del frente marítimo de El Campello (Alicante) mediante la rehabilitación de las cuevas del antiguo puerto pesquero. Investigaciones Geográficas, no 56, pp. 149-163.

VV.AA. (2005). Criterios para la elaboración del plan museológico. Ministerio de Cultura, Madrid.

\section{MATERIAL LEGAL Y ADMINISTRATIVO}

Estudio del Paisaje del Plan General de Ordenación Urbana de El Campello, Cota Ambiental S.L.

Ley 5/2007, de 9 de febrero, de modificación de la Ley 4/1998, de 11 de junio, del Patrimonio Cultural Valenciano, «BOE» núm. 71, de 23 de marzo de 2007.

\section{CARTOGRAFÍA Y RECURSOS WEB}

http://www.diarioinformacion.com/ alacanti/2016/03/08/ayuntamiento-marqproyectan-gran-area/1736412.html

http://www.marqalicante.com/Noticias/es/ El-Ministero-de-Cultura-incluye-la-Illeta-delsBanyets-y-su-entorno-entre-los-cien-paisajespatrimoniales-de-Espana-N486.html

http://vimeo.com/70770206

Visor Sigpac. Consultado en http://sigpac. mapa.es/fega/visor/ 